\title{
Stability analysis of photovoltaic system under grid faults
}

\author{
Nivedita Pati ${ }^{1}$, Babita Panda ${ }^{2}$, Bhagabat Panda ${ }^{3}$ \\ ${ }^{1,2}$ School of Electrical Engineering, KIIT University, India \\ ${ }^{1}$ Department of Electrical and Electronics Engineering, SIT Bhubaneswar, India \\ ${ }^{3}$ Department of Electrical Engineering, PMEC, India
}

\begin{tabular}{|c|c|}
\hline Article Info & ABSTRACT \\
\hline Article history: & This work includes the establishment of a Photovoltaic system connected to \\
\hline Received May 26, 2019 & $\begin{array}{l}\text { the grid by means of an inverter. The fundamental goal of the work is to } \\
\text { incorporate an advanced active power flow management scheme in order to }\end{array}$ \\
\hline Revised Oct 22, 2019 & adopt load at any weather condition along with the advantage of maximum \\
\hline Accepted Dec 5, 2019 & $\begin{array}{l}\text { active power flow and zero harmonics from PV inverter to the grid. The } \\
\text { outcome of analysis and control design of grid connected PV inverter using a }\end{array}$ \\
\hline Keywords: & $\begin{array}{l}\text { Proportional-Integral }(\mathrm{PI}) \text { control technique is based on synchronous dq } \\
\text { rotating reference frame so as to achieve maximum output voltage and record }\end{array}$ \\
\hline $\begin{array}{l}\text { Boost converter } \\
\text { MPPT }\end{array}$ & $\begin{array}{l}\text { the active power. It has been observed that the model provides a better rate of } \\
\text { stability as compared to the existing topology. }\end{array}$ \\
\hline
\end{tabular}

Photovoltaic model

Proportional-integral controller

Pulse width modulation (PWM)

This is an open access article under the CC BY-SA license.

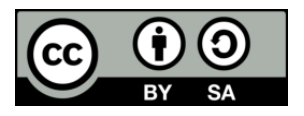

Corresponding Author:

Nivedita Pati,

School of Electrical Engineering, KIIT University,

Bhubanewsar, 751024, India.

Email: nivedita.pati@silicon.ac.in

\section{INTRODUCTION}

As fossil fuels are depleting day by day, more research is going on harvesting electrical energy from renewable energy. Among all other renewable energy sources, Solar and wind energies, are the maximum accessible and dispersed all over the universe. Utilization of photovoltaic (PV) has been rising notably by virtue of the fast advancement of power electronic techniques. Here the objective of the study is to get the maximum energy efficiency under the different operating condition and to approach the design of a robust controller having the ability to reject the noises. The main objective of the study is to coordinate the voltage, the power injected into the utility. Many earlier works have inspected different control aspects of Inverter that are connected to the grid. Most of the analysis is done to reduce the THD of the system. But very few of them focus on stability issues of grid coonected PV system. Different Power quality issues of the grid connected PV system are described by Vikas khare [1]. The author herself explained about the different types of fault analysis in grid connected photovoltaic system [2]. M. G. Molina and L. E. Juanico explained the designing of the photovoltaic structure connected to the grid [3]. The dynamic behavior of grid connected Photovoltaic system is studied under the LLLG fault by author K. Manohar [4] and [5]. The proposed work gives the information about a three-phase Pulse Width Modulated inverter modeling and its control strategy. The single staged grid connected inverter gets its input from a dc-dc converter fed through a photovoltaic input [6]. Particularly, the control design of grid connected inverter using the PI control technique has been proposed in the dq rotating frame in order to achieve maximum output voltage and maximum active power. A current control PWM technique has been suggested to provide the pulse for voltage source inverter. 
By virtue of the huge amount of interconnection of dispersed power generation to the grid in some regions, uncertainty and fluctuation of a different parameter of the power system may appear which requires proper design of controllers for stability analysis under variable conditions [7]. more importance is put on the capability of a Distributed Power Generation System (DPGS) to overcome sharp grid disruptions such as variations in voltage and frequency. This paper focuses on some desirable control techniques that DPGS can follow during damaged grid circumstances. First, a grouping of different kinds of grid faults is illustrated, and it ensured by some applications of the control technique during damaged grid circumstances. A. V. Timbus [8] and [9] analyzed some possible control techniques that DPGS can follow during faulty grid conditions followed by the grouping of different kinds of grid faults in this paper. The primary objective of the control technique is reproduction of power, and also the generation of the currents referred which can meet the grid power requirement. M.Cai [10] adopted a shunt controller for voltage dip compensation when a fault is introduced in the grid. In [11, 12] dynamic stability of a Photovoltaic structure connected with a distribution system is analyzed. Reference [13] and [14] has adopted a control technique to analyze the dynamic stability of the PV System.

\section{PROPOSED ACTIVE POWER FLOW CONTROL SCHEME FOR STABILITY ANALYSIS}

This section describes the internal structure proposed control design which consists of an external voltage circuit and an internal current circuit [15]. The proposed model is discussed in Figure 1. It consists of a Solar (PV) system, step up converter, which is then interfaced with an inverter (VSI), a distribution network, load and grid with a power flow controller. Figure 1 describes the circuit diagram of the proposed structure.

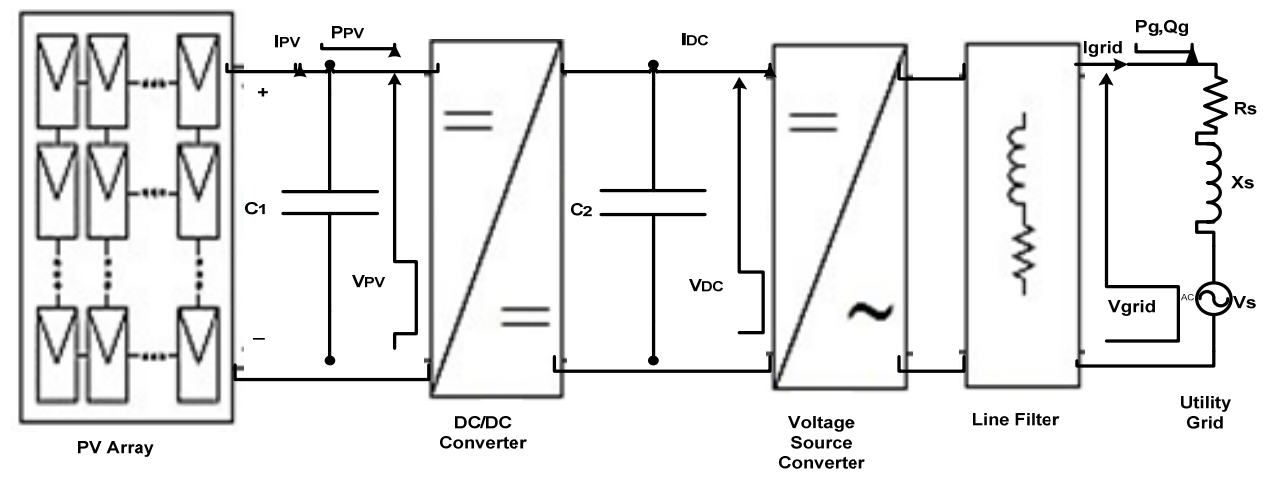

Figure 1. Block diagram of Grid connected PV system

The suggested structure is built to control the various parameters like current, voltage and power injected into the utility [16]. The 305 Solar Panel is being selected for designing of PV system using MATLAB. MPPT approach is employed for enhancing the efficiency of the solar panel. The Perturb \& Observe $(\mathrm{P} \& \mathrm{O})$ method is selected as the MPPT tracker whose primary goal is to obtain rapid and correct tracking act and reduces oscillations with respect to changeable weather conditions. $\mathrm{P} \& \mathrm{O}$ method implementation is quite cheap. The output of the boost converter which is $1200 \mathrm{~V} \mathrm{DC}$ is converted into $800 \mathrm{~V}$ $\mathrm{AC}$ by a voltage source inverter, then that voltage is increased to $11 \mathrm{KV}$ by a step-up delta/star transformer.

\subsection{Internal structure of control system}

Figure 2 represents the circuit diagram representation of the control structure. It includes the abc-dq transformation block, PLL block, PI controller and the PWM generator. The step-up converter to steps up the voltage of the solar MPPT system while the MPPT generates the pulse for the converter. The PV system and boost converters are connected to the voltage source converter.

Int J Pow Elec \& Dri Syst, Vol. 11, No. 2, June 2020 : 931 - 941 


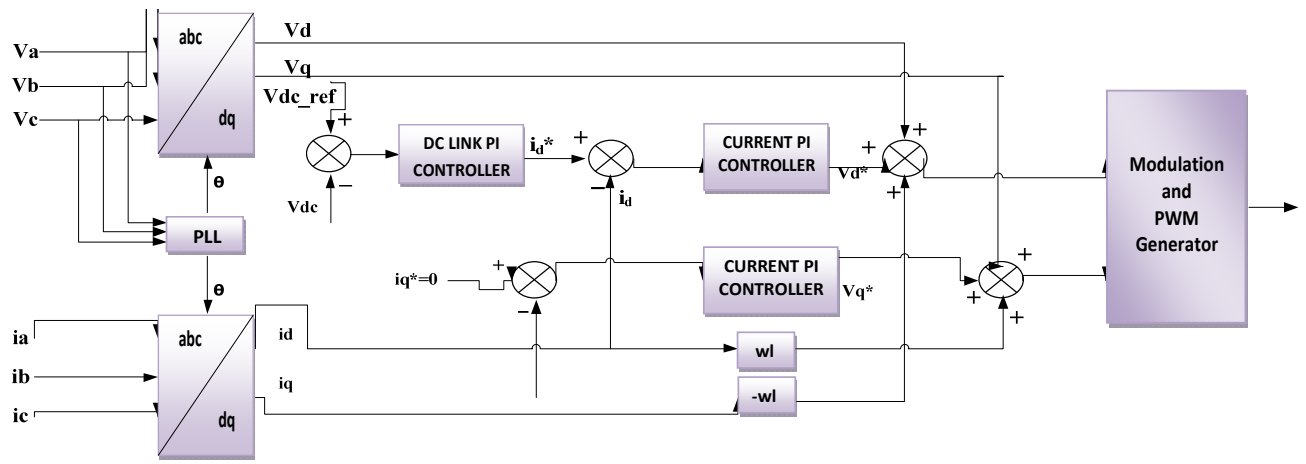

Figure 2. Block diagram of internal control structure

The speed of the control loop depends on the bandwidth of the loop. So by varying the cut-off frequency of open loop transfer function (transfer function of inner loop multiplies with PI transfer function), the differential speeds can be achieved. Since some of the state variables are multiplied with the control inputs, the mathematical model of the converter becomes nonlinear.

\subsection{DC-link voltage control scheme}

The active power is restrained by the voltage at the DC-link with its desired value. Figure 3 shows the internal structure of the dc-link voltage management strategy. It has six components: MPPT, voltage compensator, limiter, current components, and integrator. Here $u_{d r e f}$ is a reference DC voltage recorded by the maximum power point technique [17]. ${ }^{u_{d r e f}}$ correlates with the $u_{d c}$ and the output signal is fed to the PI compensator. The compensator sets up ${ }^{i}$ dref which is the ref. the current value of the d-axis component. The current controller sets up actual d-axis current $i_{d}$ from ref. current value ${ }^{i_{d r e f}}$ and then $\left(i_{p v}-i_{d}\right)$ is passed through an integrator which generates $u_{d c}$.

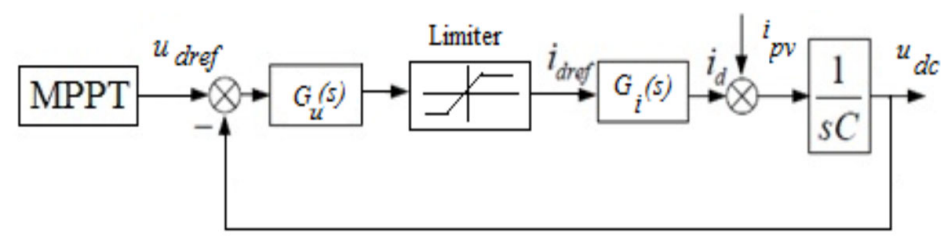

Figure 3. Inside structure of DC link voltage control scheme

$$
\begin{aligned}
& u_{d c}=\frac{1}{C} \int i_{c} d t \\
& u_{d c}=\frac{1}{C} \int\left(i_{p v}-i_{d}\right) d t \\
& u_{d c}(s)=\frac{1}{C s}\left[i_{p v}(s)-i_{d}(s)\right] \\
& i_{d}(s)=\frac{1}{T s+1} i_{d r e f}(s) \\
& i_{d r e f}(s)=G_{u}(s)\left[u_{d r e f}(s)-u_{d c}(s)\right]
\end{aligned}
$$


Where $\mathrm{C}$ is the capacitor, ic is current through the capacitor, ipv is the PV current, udc is the voltage across DC link, udref the DC voltage reference, id is d-axis component of grid current, idref is it's a reference value.

\subsection{Internal current loop}

The $d-q$ transformation matrix is used for the conversion of three-axis grid voltage and current to the dq reference frame. The AC grid voltage and current are converted into DC values with the help of abc $\rightarrow$ dq transformation matrix, by regulating the variables. The phase angle is calculated with the help of PLL (Phase Lock Loop) [18] which is further required for synchronization of grid voltage with controlled current. To get the unity power factor, iqref*(reference reactive current) is set to zero. The Proportional-Integral controllers provide the voltage outputs $\left(\mathrm{Vd}^{*}, \mathrm{Vq}^{*}\right)$ which fed to the PWM generator to generates the pulses used to for Inverter [19].

$$
\left[\begin{array}{c}
\mathrm{I}_{\mathrm{d}} \\
\mathrm{I}_{\mathrm{q}} \\
\mathrm{I}_{0}
\end{array}\right]=\sqrt{\frac{2}{3}} \times \mathrm{T} \times\left[\begin{array}{c}
\mathrm{I}_{\mathrm{a}} \\
\mathrm{I}_{\mathrm{b}} \\
\mathrm{I}_{\mathrm{c}}
\end{array}\right]
$$

By using the above formula given in (6), the abc-dq transformation is made where $\mathrm{T}$ is the transformation matrix.

As the voltage of grid is cannot be managed, the ultimate desirable choice of governing the action of the arrangement is by regulating the Id and Iq that is injecting to the grid. Figure 4 depicts output of a compensator $(\mathrm{Ud})$, is the control signal focusing on minimizing error as:

$$
e_{d}=i_{d r e f}-i_{d}
$$

Correspondingly, the error signal that another regulator processes,

$$
e_{q}=i_{q r e f}-i_{q}
$$

The error commands are fed to a PI regulator. The PI regulator constants are selected so that,

$$
\begin{aligned}
& K_{p}=\frac{L}{\tau_{i}} \\
& K_{i}=\frac{R}{\tau_{i}}
\end{aligned}
$$
in Figure 4.

where ${ }^{\tau_{i}}$ is the time constant of the circuit. The internal control structure of the system is shown

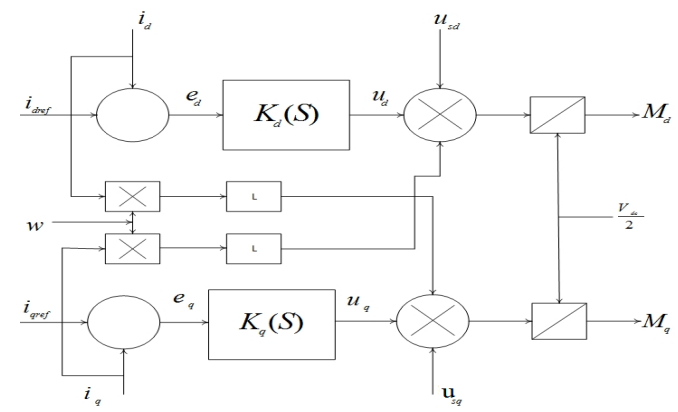

Figure 4. Basic structure of pulse generation scheme

The PWM modulating commands are, 


$$
\begin{aligned}
& m_{d}=\frac{2}{V_{d c}}\left[U_{d}-L w i_{q}+U_{s d}\right] \\
& m_{q}=\frac{2}{V_{d c}}\left[U_{q}+L w i_{d}+U_{s q}\right]
\end{aligned}
$$

Where $m_{d}, m_{q}$ are d-axis and q-axis factors of modulating commands, Vdc is the voltage at DC link, $U_{d}, U_{q}$ are control signals of d-axis and q-axis, Usd, Usq are refined voltage of VSI, $w$ is the grid frequency. The pulses are developed by conversion of $d$ and $q$ signals into a,b,c signals. By regulating md and $\mathrm{mq}$, the id and iq quickly follow their corresponding reference signals idref and iqref [20]. Then active and reactive power of Photovoltaic arrangement are given as:

$$
\begin{aligned}
& P_{s}=\frac{3}{2} U_{s d} i_{d} \\
& Q_{s}=-\frac{3}{2} U_{s d} i_{Q}
\end{aligned}
$$

As the voltage at the grid is unmanageable, the ultimate practicable approach of monitoring the arrangement is by regulating grid currents Id and Iq. As active power flow is reliant on the current Id, and reactive power inserted to the grid is dependent on the current Iq and thus Iqref $=0$ is set forcefully to make zero reactive power $[21,22]$.

\subsection{Simulink environment}

The validity of the system is checked with the help of computer simulations. The MATLAB/SIMULINK software is used to simulate the final system and for unusual circumstances, the analysis is done. The symmetrical and unsymmetrical faults are created on the distribution network, for the analysis of system behavior under fault [23].

\section{SIMULATION OUTCOMES OF FAULT ANALYSIS}

The simulation is conducted in order to achieve stability of the photovoltaic system under different conditions of grid faults. The transient state stability of the system may be analyzed by many methods; here some aspects are taken into account. The faults on the grid can be divided into two main groups.

a) Symmetrical fault: When an equal decrease in the magnitude of the grid voltage occurs in all three phases whereas the system remains balanced. Symmetrical faults are not uncommon (they do happen often: bus faults, lightning strikes in substations etc).

b) Unsymmetrical fault: When an unequal decrease in grid voltage occurs with alternation in phase in between. This category of fault arises as more than one phase is shorted to ground or to one another.

The effectiveness of the control system is checked by considering three cases of grid faults. In each of the cases, the result analysis is carried out that has been recorded for stability analysis [24].

case-1: Three phase to ground fault (LLLG fault): Three phases to ground fault is a familiar fault in the industrial climate. The outcome of the PV circuit with a LLLG fault of $0.3 \mathrm{sec}$ to $0.4 \mathrm{sec}$ is analyzed in this section.

case-2: LLG fault in distribution network: In this case, a double line to ground fault is simulated from 0.3 sec to $0.4 \mathrm{sec}$. When this type of fault occurs a sudden power surge is experienced in the converter. The voltage of the converter rises rapidly and then recovers with an oscillation that lasts for a few cycles. This response is generated with the PI controller.

case-3: LG fault in distribution network: In this case, a single line to ground fault is simulated.

The Figure 5 illustrates the Simulation model of the grid connected PV system. The sub-system of the PV source includes a PV block, MPPT controller along with step up converter interfaced to the grid via voltage source inverter. Table 1 gives system parameters data and specifications [25]. Here the system is certified under the least fault circumstances. 


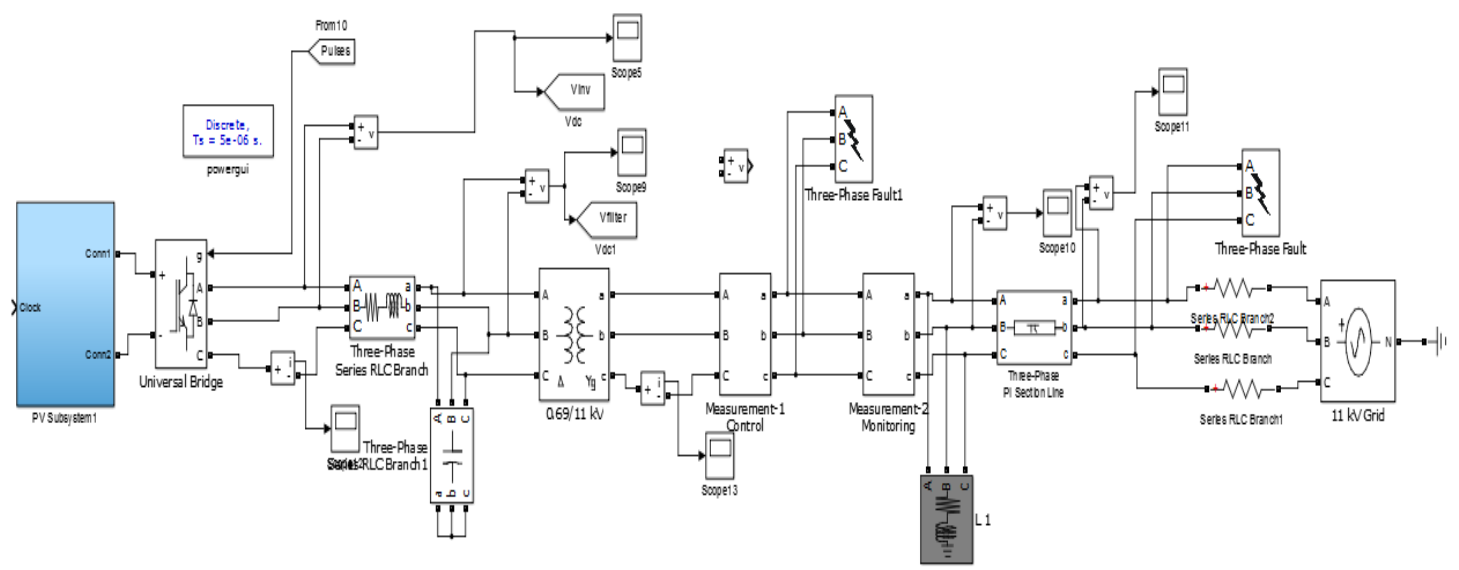

Figure 5. Simulation model of the proposed system

Table 1. System Parameter and Specifications

\begin{tabular}{cccc}
\hline Parameter & Values & Parameter & Values \\
\hline The voltage at the Grid & $11 \mathrm{KV}$ & $\mathrm{V}_{\mathrm{dc}}$ & $1200 \mathrm{~V}$ \\
Supply frequency & $50 \mathrm{~Hz}$ & Fsw_inv & $2 \mathrm{kHz}$ \\
Filter Inductor & $10 \mathrm{mH}$ & Filter Capacitor & $100 \mu \mathrm{F}$ \\
Inverter voltage & $1200 \mathrm{~V}$ & Inverter output voltage after filtering & $800 \mathrm{~V}$ \\
Three phase line & $15 \mathrm{~km}$ length & Load & $5 \mathrm{MW}, 100 \mathrm{VAR}$ \\
\hline
\end{tabular}

\subsection{Three phase to ground fault (LLLG fault)}

The output waveforms of proposed structure with a LLLG fault are illustrated below. At $t=0.3 \mathrm{sec}$ to $0.4 \mathrm{sec}$, LLLG fault is inserted into the system. Figure 6(a) shows the waveform of DC voltage generated by the boost converter. Figures 6(b) and 6(c) depict with LLLG fault the nature of 3-phase current and voltage at the grid. Figures $6(\mathrm{~d})$ and $6(\mathrm{e})$ show the variation of powers fed to the grid.

Figure 6(a) illustrates the waveform of the DC voltage produced by the step-up converter. Before the application of the fault, DC voltage attains a value of $1200 \mathrm{~V}$. During the fault, DC voltage increases suddenly from 1200 to $1600 \mathrm{~V}$. Just after $0.42 \mathrm{sec}, 1200 \mathrm{~V}$ is achieved.

Figure 6(b) depicts the response of a three-phase current in the course of the three-phase fault. Ahead of the introduction of fault, current is settled at $5 \mathrm{~A}$. When a fault is introduced at $0.3 \mathrm{sec}$ the current rises nearly to $180 \mathrm{~A}(\max )$ and certainly the current recovers its steady value of $5 \mathrm{~A}$ after the fault period.

Figure 6(c) indicates the nature of three-phase voltages at the time of LLLG fault. Ahead of the application of fault, voltage is kept at $8 \mathrm{KV}(\max )$. At the time of application of fault, the voltage at the grid is zero from 0.3 to $0.4 \mathrm{sec}$. Later $0.4 \mathrm{sec}$, voltage settles to its constant value.

Figure 6(d) shows the waveform of active power fed to the grid at the time of the fault period from $0.3 \mathrm{sec}$ to $0.4 \mathrm{sec}$. In the course of the fault period, both active, as well as reactive power, remains zero. At $0.45 \mathrm{sec}$ power settles to its normal value.

In Figure, 6(e) it is observed that there is a very slight change in reactive power just after 0.4 seconds. Then after some time, it settles to its steady-state value. 


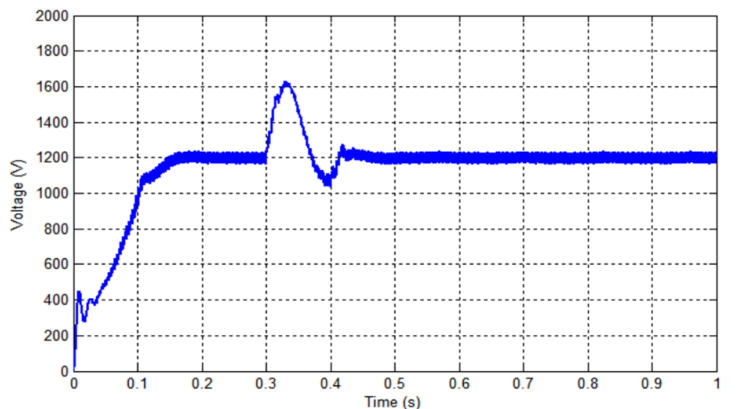

(a)

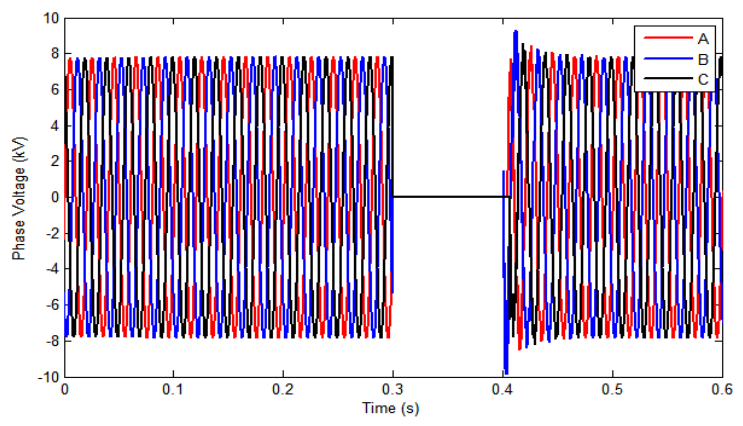

(c)

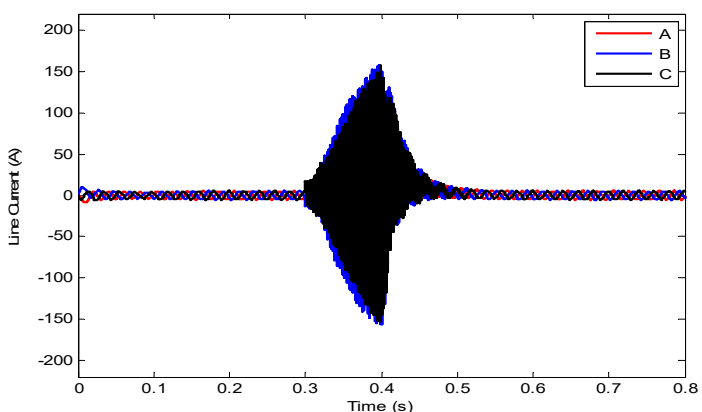

(b)

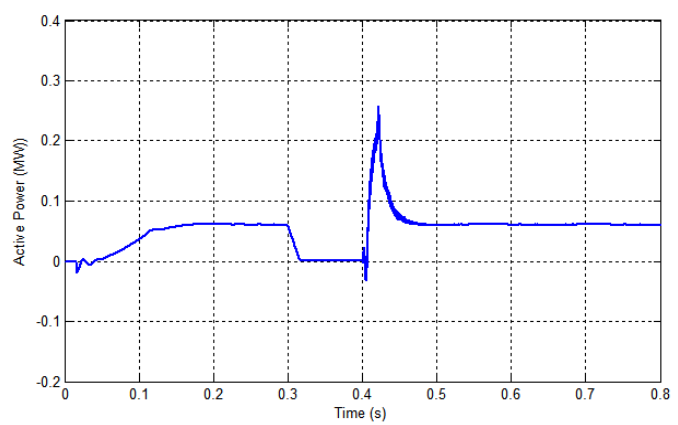

(d)

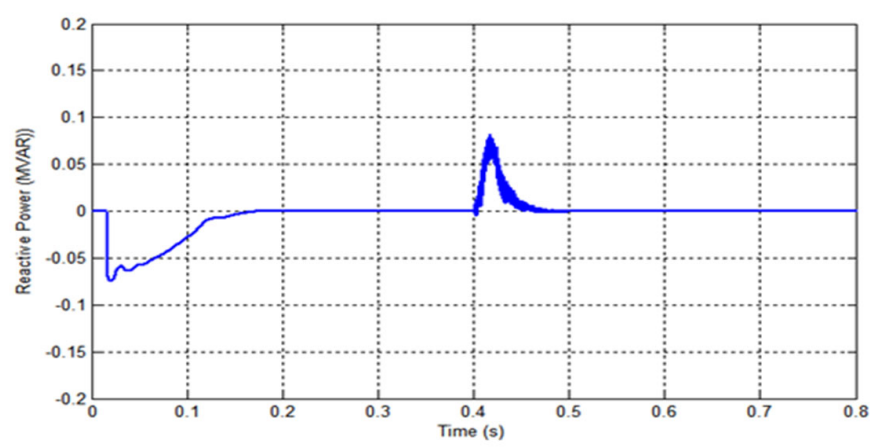

(e)

Figure 6. (a) DC voltage generated vs.time, (b) 3-phase current vs.time at grid, (c) 3-phase voltage vs time at grid, (d) Active power at grid, (e) Reactive power vs. time at the grid with LLLG fault

\subsection{LLG fault at distribution network}

The Figure 7(a) shows the DC voltage generated by the Step up converter along LLG fault. Figures 7(b) and 7(c) depict 3-phase current and voltages at the grid along with LLG fault. Figures 7(d) and 7 (e) illustrate the changes in active and reactive power. Figure 7(a) shows the DC voltage generated by the boost converter is disrupted more than LLLG fault. With $0.3 \mathrm{sec}$ DC voltage oscillates between 1200 to $1600 \mathrm{~V}$ and then decreases to $1200 \mathrm{~V}$ after the fault. Later at $0.41 \mathrm{sec}$, voltage settles to its steady-state value.

Figure 7(b) indicates the nature of three-phase voltages during LLG fault. The voltage at the grid is disturbed from 0.3 to $0.4 \mathrm{sec}$. After $0.4-\mathrm{sec}$ voltage settles to its regular value.

When a fault is introduced at $0.3 \mathrm{sec}$ the current rises nearly to $100 \mathrm{~A}$ (max) which is shown in Figure 7(c). At $0.42 \mathrm{sec}$, current attains its original value. From Figure 7(d) it is observed that the real and reactive power inserted to the grid is highly disrupted at the time of the LLG fault of $0.3 \mathrm{sec}$ to $0.4 \mathrm{sec}$. At $0.43 \mathrm{sec}$ power attains its steady-state value. 
Figure 7(e) shows the changes in the reactive power in the course of the fault period. The output waveform depicts that the reactive power is negative during the fault period. Just after the clearance of fault, growth is seen, then after some time, it settles to its normal value.

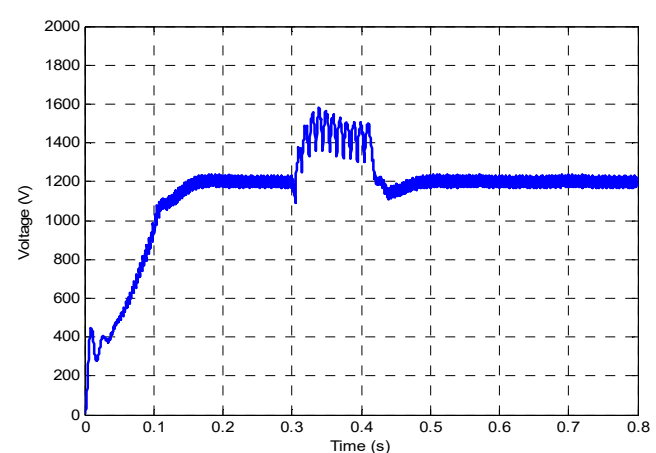

(a)

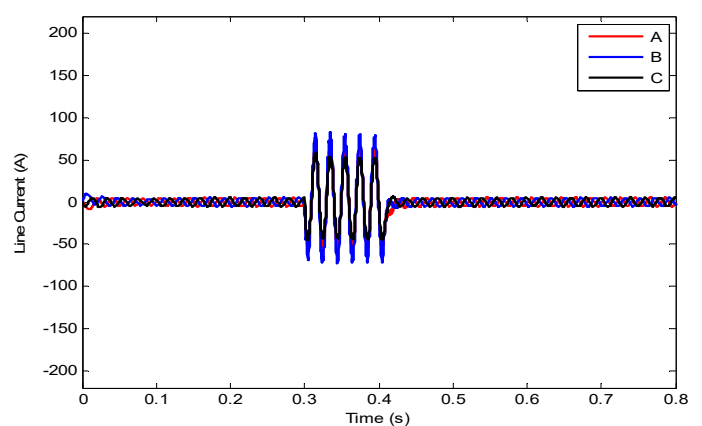

(c)

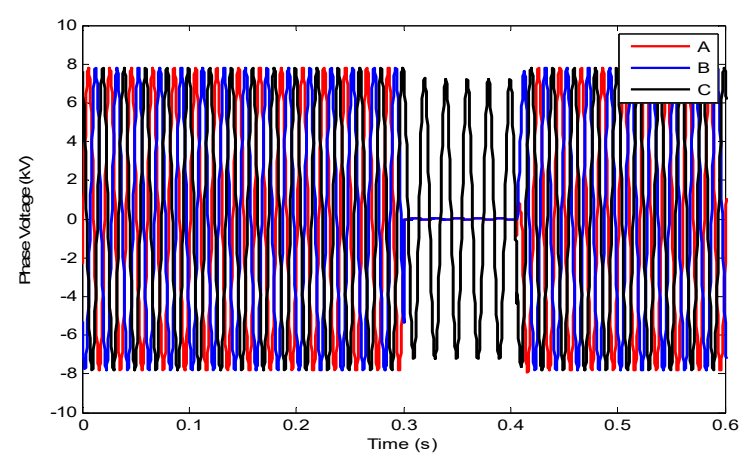

(b)

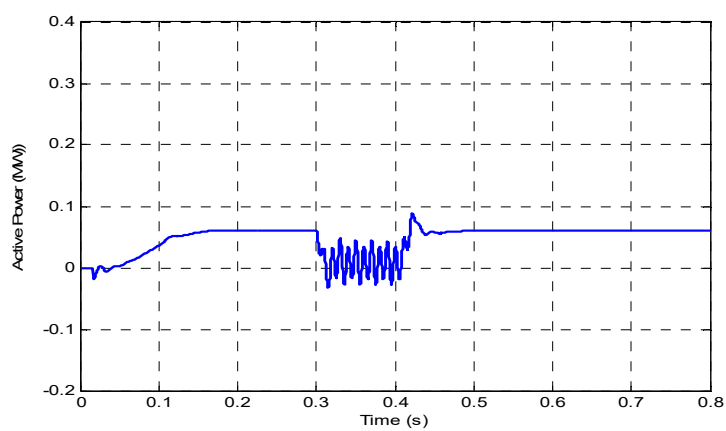

(d)

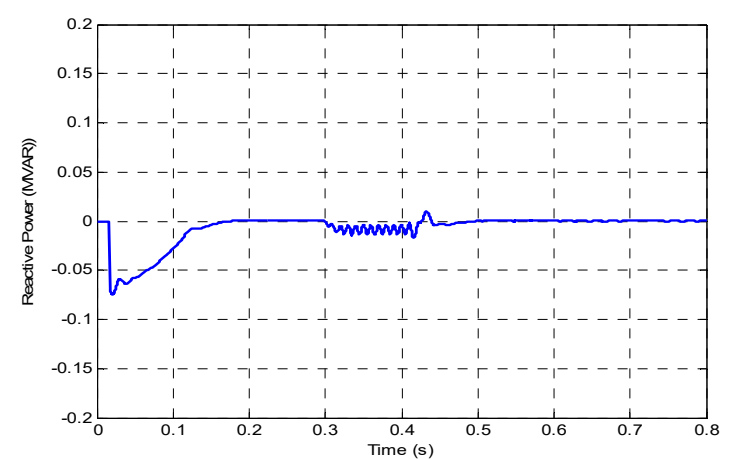

(e)

Figure 7. (a) Converter voltage vs. time with LLLG fault, (b) Grid voltage vs. time with LLLG fault (c) Grid current with LLG fault, (d) Active power at the grid with LLG fault, (e) Reactive power vs. time at the grid with LLG fault

\subsection{LG Fault at distribution network}

Figure 8(a) shows the voltage generated by the converter with LG fault. Figures 8(b) and 8(c) show 3 -phase current and voltages at the grid with LG fault. Figures $8(\mathrm{~d})$ and $8(\mathrm{e})$ show changes in active and reactive power fed to the grid.

Figure 8(a) shows the voltage generated by the converter with LG fault is disturbed less than LLG fault during the LG fault of $0.3 \mathrm{sec}$ to $0.4 \mathrm{sec}$. At $0.42 \mathrm{sec}$ the voltage reaches its regular value that is $1200 \mathrm{~V}$. With $0.3 \mathrm{sec}$ DC voltage oscillates between 1200 to $1400 \mathrm{~V}$ and then decreases to $1200 \mathrm{~V}$ after the clearance of fault. After $0.42 \mathrm{sec}$ voltage settles to its regular value. In Figure 8(b), it is shown that in the course of the LG fault the grid voltage is disturbed from 0.3 to $0.4 \mathrm{sec}$. After $0.4 \mathrm{sec}$ voltage settles to its regular value. 
Figure 8(c) depicts the current response for the SLG fault. The current rises from 5 A to $100 \mathrm{~A}$ instantly during the fault. The fault is cleaned $1 \mathrm{sec}$ later and the current grasp the normal value at $\mathrm{t}=0.42 \mathrm{~s}$.

Figure 8(d) shows the waveform of active power fed to the grid. It is visible that the power injected to the grid is less disrupted during the LG fault than the LLG fault from $0.3 \mathrm{sec}$ to $0.4 \mathrm{sec}$. At $0.42 \mathrm{sec}$ power attains its steady state value because of the action of a robust controller. Figure $8(\mathrm{e})$ shows the changes in reactive power in the course of the fault period. It is less disrupted than LLG fault.

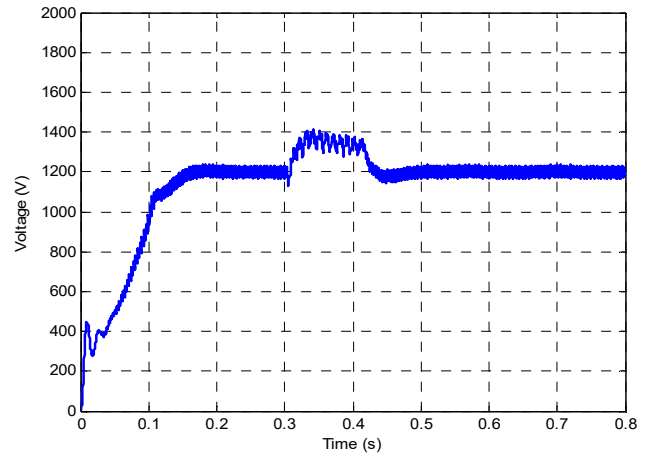

(a)

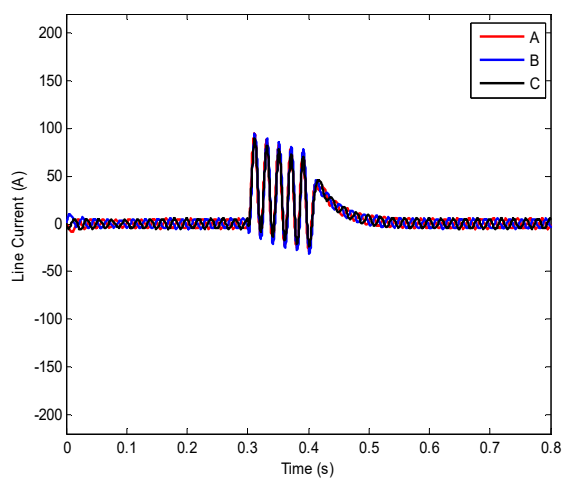

(c)

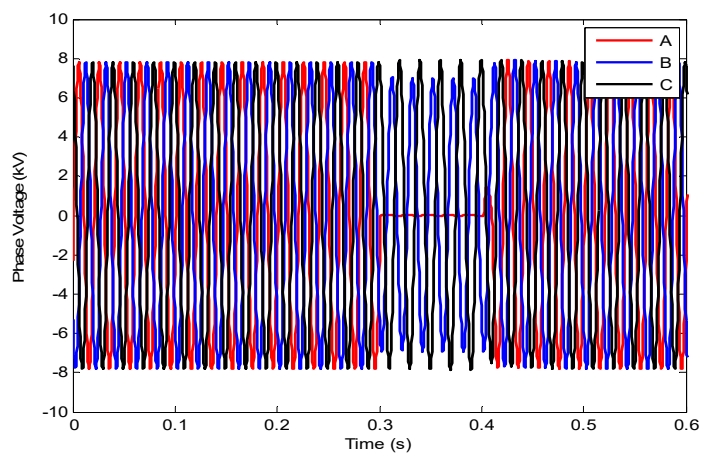

(b)

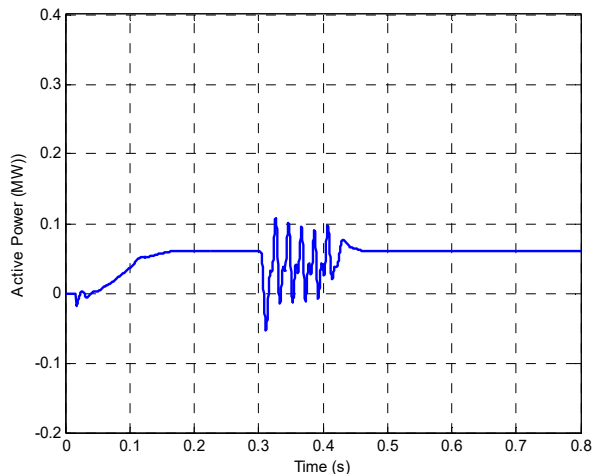

(d)

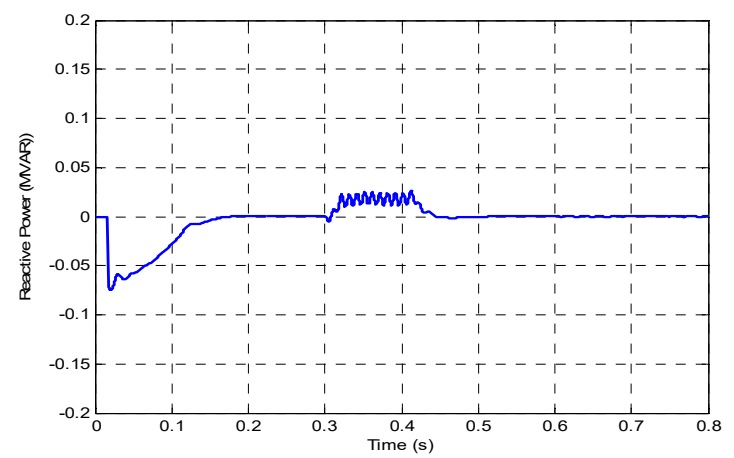

(e)

Figure 8. (a) Converter voltage with LG fault, (b), Grid voltage with SLG fault, (c) Grid current with SLG fault, (d) Active power at the grid with SLG fault, (e) Reactive power at the grid with SLG fault

\section{CONCLUSION}

Initially, the system is simulated without any fault. The three types of faults are presented and the impact on the system is studied under the presence of different types of faults. The simulation result is given below for all types of faults. Nevertheless, there are countless processes to analyze the dynamic stability of the structure, only important aspects are taken into consideration. This paper describes the effective 
achievement of the system. In this paper, the structure is certified under the least damaged circumstances i.e. the symmetrical as well as unsymmetrical fault. Just after the fault, system parameters retain their original values because of the robustness of the controller. The correctness of the current control scheme is demonstrated by the result analysis. The output waveform compiled the validity of the used control techniques since the delivered powers pursue the regular values, provided by the MPPT controller of the PV system, both in a normal and abnormal condition.

\section{REFERENCES}

[1] V.khare, S.Nema, and P.Baredar, "Power quality disturbances in grid connected solar system its prevention", International Journal of Engineering and Innovative Technology (IJEIT), Vol.1, Issue.5, pp 252-255, 2016.

[2] P. K. Hota, Babita Panda, Bhagabat Panda, "Fault analysis of grid connected photovoltaic system", American Journal of Electrical Power and Energy Systems, Vol. 5, No. 4,pp. 35-44, 2016.

[3] M. G. Molina and L. E. Juanico, "Dynamic modeling and control design of an advanced photovoltaic solar system for distributed generation application", Journal of Electrical Engineering: Theory and Application (JEETA), Vol. 1, No. 3, pp.141-150, 2015.

[4] K.Manohar and P.Sobha Rani "MPPT and simulation for a grid-connected photovoltaic system and fault analysis", International Journal of Engineering and Science (IJES), Vol.1, Issue.2, pp.158-166, 2014.

[5] L. B. G. Campanhol1, S. A. Oliveira da Silva, V. D. Bacon, A. A. O. Junior, "Three-Phase Grid-Connected PV System Operating with Feed-Forward Control Loop and Active Power- Line Conditioning Using NPC Inverter", IECON Annual Conference of the IEEE Industrial Electronics Society, 2016.

[6] V. N. Lal; S. N. Singh "Control and Performance Analysis of a Single-Stage Utility-Scale Grid-Connected PV System", IEEE Systems Journal, Vol. 11, issue 3, pp. 1601-1611, 2017.

[7] S. Izumi, Y. Karakawa, X. Xin, T. Yamasaki, "Stability Analysis of Power Systems with Photovoltaic Generators", IEEE Conference on Decision and Control (CDC), 2016.

[8] A.V.Timbus, P.Rodriguez, R.Teodorescu, M.Liserre and F.Blaabjerg, "Control strategies for distributed power generation systems operating on the faulty grid", IEEE International Symposium on Industrial Electronics, pp.1601-1607, 2016.

[9] Y.Shi, Lu .Wang, Hui Li, "Control system design and Stability Analysis for a three phase SiC-based Filter-less Grid-connected PV Inverter", IEEE Applied Power Electronics Conference and Exposition (APEC), 2018.

[10] W.Cai, H. Ren, Y.Jiao, M.Cai, X.Cheng, "Analysis and Simulation for Grid-Connected Photovoltaic System based on MATLAB", International Conference on Electrical and Control Engineering (ICECE), Yichang, 2011, pp.63-66.

[11] IEEE, "IEEE standard for interconnecting distributed resources with electric power systems," Standards Coordinating Committee, IEEE Standards 1547, 2003.

[12] A.Yazdani, P.P.Dash, "A Control Methodology and Characterization of Dynamics for a Photovoltaic (PV) System Interfaced with a Distribution Network" IEEE Transactions on Power Delivery, Vol.24, No.3, pp.1538-1551, July 2009.

[13] F.Blaabjerg, R.Teodorescu, M. Liserre, A.V.Timbus, "Overview of Control and Grid Synchronization for Distributed Power Generation Systems", IEEE Transactions on Industrial Electronics, Vol.53, No.5, pp.1398-1409, Oct. 2006

[14] B.Saritha, E .Chris S, H. Shawn D and C.Jianwu, "Analysis and Control of Photovoltaic System: Application to a high penetration Case Study", IEEE Systems Journal, Vol.6, No. 2, 2012.

[15] R.Sunny, R.Anto, "Harmonics Control and Performance Analysis of a Grid-Connected Photovoltaic System", International Conference on Advanced Computing and Communication Systems (ICACCS), Coimbatore, pp.1-6, 2013.

[16] Z.Dejia, Z.Zhengming, M.Eltawil, Y.Liqiang, "Design and Control of a Three-Phase Grid-connected photovoltaic System with Developed Maximum Power Point Tracking", Twenty-Third Annual IEEE Applied Power Electronics Conference and exposition, Austin, TX, pp.973-979, 2008.

[17] S.Meshram, G.Agnihotri, S.Gupta, "An Efficient Constant Current Controller for PV Solar Power Generator Integrated with the Grid", Fifth IEEE Power India Conference, Murthal, pp.1-6, 2012.

[18] M.F.Schonardie, D.C.Martins, "Application of the dq0 Transformation in the Three-Phase Grid-Connected PV Systems with Active and Reactive Power Control", IEEE International Conference on Sustainable Energy Technologies, Singapore, pp. 18-23, 2008.

[19] S. B. Kjaer, J. K. Pedersen, F. Blaabjerg, "A Review of Single-Phase Grid-Connected Inverters for Photovoltaic Modules”, IEEE Trans. IndAppl., Vol.41, No.5, pp.1292-1306, Sep./Oct. 2005.

[20] J.M.Carrasco, L.G.Franquelo, J.T. Bialasiewicz, E.Galvan, R.C.P.Guisado, M.A.M.Prats, J.I.Leon, N.MorenoAlfonso, "Power Electronic Systems for the Grid Integration of Renewable Energy Sources: A survey", IEEE Trans.on Ind. Electron, Vol.53, No.4, Aug. 2006, pp.1002-1016.

[21] J.H.R.Enslin, P.J.M.Heskes, "Harmonic Interaction between a Large Number of Distributed Power Inverters and the Distribution Network", IEEE Trans. on Power Electron, Vol.19, No.6, pp.1586-1593, Nov. 2004.

[22] N.Srisaen, A.Sangswang, "Effect of PV Grid-Connected System Location on a Distribution System", Proc. ofIEEE Asia Pacific Conf. on Circuit and Systems, pp.852-855, Dec. 2006.

Int J Pow Elec \& Dri Syst, Vol. 11, No. 2, June 2020 : 931 - 941 
[23] S.A.Lakshmanan, A.Jain, B.S. Rajpurohit, "Grid voltage monitoring techniques for a single phase grid connected solar PV system", IEEE 6th India International Conference on Power Electronics (IICPE), Kurukshetra, pp.1-6, 2014.

[24] B.K.Naik, M.Das, T.K.Chatterjee, K.Chatterjee, "Study and implementation of synchronization algorithm in threephase grid connected PV system", 3rd International Conference on Recent Advances in Information Technology (RAIT), Dhanbad, pp.304-309, 2016.

[25] Y.Teng, C.Xiong, C.Li, Z.Zhang, X.Yu, W.Zhang, "Study on harmonic and reactive current detection in gridconnected PV Power stations", IEEE International Conference on Progress in Informatics and Computing (PIC), Nanjing, 2015, pp. 433-437.

\section{BIOGRAPHIES OF AUTHORS}
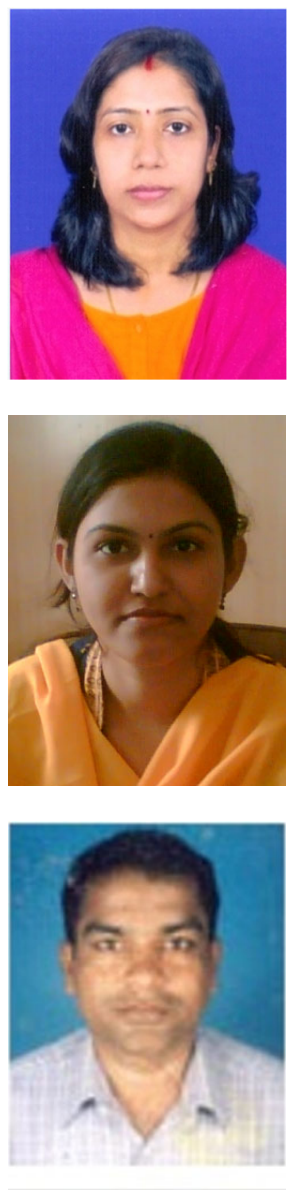

Nivedita Pati, received the M.Tech degree from National Institute of Technology, Rourkela, Odisha, India with a specialization in Control and Automation.

She is currently persuing her PhD in KIIT University and is working as an Assitant Professor in Silicon Institute of Technology, Bhubaneswar,Odisha, India from 2012.

Her research interest includes Control Systems and Renewable Energy She is a member in IEEE since last 7 years and has 5 IEEE conference and one journal publication.

Babita Panda received the B.Tech. degree in electrical engineering from the BIET, Bhadrak, $\mathrm{M}$.Tech and $\mathrm{Ph} \mathrm{D}$ degree from Kalinga Institute of Industrial Techonology deemed to be University. She is working as an Assistant Professor in the department of Electrical Engineering at KIIT university since $16^{\text {th }}$ August 2012.Her research interests include distributed generation, renewable energy and power Electronics.

Dr. Bhagabat Panda received the Ph.D degree from Utkal University,M.Tech degree from and B.Tech degree in Electrical Engg from VSSUT Burla, Sambalpur, Odisha. He is working as an Associate Professor in the department of Electrical Engineering at PME College, Barhampur.His research interests include distributed generation, renewable energy and power System. 